\title{
Public knowledge of warning signs and risk factors of cerebro-vascular stroke in Ismailia Governorate, Egypt
}

\author{
Ahmed Osama', Yossri Ashour ${ }^{1}$, Reda Abd El-Razek ${ }^{1 *}$ and Ibrahim Mostafa²
}

\begin{abstract}
Background: Knowledge and awareness of cerebro-vascular stroke (CVS) warning symptoms and risk factors is deficient in the general population in the developing countries.

Objective: To evaluate the knowledge and attitude about warning symptoms and risk factors of cerebro-vascular stroke among a sample of people living in Ismailia Governorate, Egypt.

Methods: This study was conducted at two selected areas of Ismailia Governorate, an urban area and a rural area. Seven hundred and twenty participants were included in the study (360 form the urban area and 360 from the rural area). Face-to-face questionnaire-based interviews were administered to the participants. The survey tool is a 9item questionnaire translated in Arabic, designed to evaluate the knowledge and attitude about warning symptoms and risk factors of cerebro-vascular stroke.

Results: According to the participants, the main source of knowledge about CVS was from seeing someone with stroke, the main risk factor of CVS was hypertension, the most frequent warning symptom of CVS was paralysis of one side, and the most frequent action to be taken with the onset of CVS was direct transfer to the hospital.
\end{abstract}

Conclusion: Hypertension was the mostly known risk factor. Only few participants were aware of diabetes mellitus as a risk factor for cerebro-vascular stroke. This information will be useful for planning CVS prevention campaigns.

Keywords: Public knowledge, Warning symptoms, Risk factors, Cerebro-vascular stroke

\section{Introduction}

Cerebro-vascular stroke (CVS) is a medical emergency. It causes permanent neurological damage, complications, and death [1]. Knowledge and awareness of its warning symptoms and risk factors is deficient among the general population in the developing countries. It is poorly understood by the public and has been associated with numerous misconceptions [2].

To counter the effects of CVS, the time from its onset to hospital arrival must be adjusted in order to provide timely and effective treatment. Many factors contribute to the delay in seeking appropriate treatment. The principal factor is the lack of public knowledge regarding stroke symptoms and the need for a rapid response $[3,4]$.

\footnotetext{
*Correspondence: Dr.reda_abdelrazek@yahoo.com

${ }^{1}$ Department of Neuropsychiatry, Faculty of Medicine, Suez Canal University, Ismailia, Egypt

Full list of author information is available at the end of the article
}

Without public knowledge and the proper attitude and practice, stroke burden cannot be reduced. Lack of knowledge about stroke symptoms, delayed hospitalization, and hesitancy in hospital admission contribute to high mortality and morbidity in stroke [5]. There is a lack of knowledge and loss of concern about the treatment of the CVS risk factors and appropriate lifestyle changes, which can decrease the incidence of stroke and morbidity among stroke survivors [6].

\section{Aim}

To assess the level of public knowledge, awareness and attitude toward CVS warning symptoms and risk factors in Ismailia Governorate, Egypt.

\section{Patients and methods}

This study was conducted at two selected areas of Ismailia Governorate: an urban area (El-Shiekh Zayed District, 
Ismailia city) and a rural area (Abu-sultan village, Fayed City). The study was a cross-sectional community-based survey (door-to-door survey). The participants were selected by random pre-selection of specific blocks of household identified on published maps. A total of 720 participants were included in the study (360 form the urban area and 360 from the rural area).

All the participants aged 18 years old and above were included in the study. The participants with history or with current manifestations of CVS were excluded. Those who did not consent to the study were excluded.

Face-to-face questionnaire-based interviews were administered to the participants. A9-item questionnaire translated to Arabic was used. The English version translated into Arabic was linguistically validated. The translation and linguistic validation was performed in the following manner to ensure conceptual equivalence between the original and its translation: forward translation by two independent Arabic translators, one of whom was aware of the concepts being examined in the translated questionnaire, and back translation by two professional English speakers was done. All required steps were done to ensure both content and face validity of the translated measure before being applied to the sample population. The version was applied in a pilot study on $10 \%$ of the study sample; 72 participants (36 form the urban area and 36 from the rural area) were excluded from the total sample; and to be sure that the statements were understood in the same way by all, the statements were reformulated several times to ascertain that they were understood in the same way.

The questionnaire which was designed to evaluate knowledge of warning symptoms and risk factors of CVS had been used in previous studies [7-9]. The questionnaire is in two parts: The first part elicited demographic information including name, age, sex, education, occupation, marital status, and history of CVS among family members. The second part elicited knowledge of warning symptoms and risk factors of CVS. Participants were asked if they ever read or heard about CVS and about the source of their knowledge about CVS. Their knowledge of risk factors for CVS was assessed by open-ended and then close-ended questions about hypertension, diabetes mellitus, smoking, old age, ischemic heart disease, elevated serum cholesterol level, alcohol intake, previous stroke, previous TIA, stress, inactivity, and family history of CVS and obesity. Their knowledge of the warning symptoms of CVS was assessed by open-ended and then by close-ended questions about weakness or paralysis of one side of the body, speech disturbance, numbness of one side of the body, loss of consciousness, loss of vision, headache, mouth deviation, vomiting, and dizziness. They were also asked about what they will do on seeing a patient with CVS (call pharmacist, call general practitioner (GP), go to the neurologist, go directly to the hospital, call the herbalist, or call the religious person). Lastly, the participants were asked about the preferred time to go to the hospital after CVS.

The study was approved by the Ethics committee of Suez Canal University, Faculty of Medicine, in May 2013 and conducted from January 2014 till June 2014. An informed consent was taken from all the participants in the study.

\section{Statistical analysis}

The data collected were processed using SPSS ver. 16.0. Continuous data were expressed in the form of mean \pm SD. Student's $t$ test was used to compare numerical data, while categorical data were compared using chi-square test. $P$ value $<0.05$ was considered significant, and $P$ value $<0.01$ was considered highly significant.

\section{Results}

Out of 720 participants, 360 (50\%) with age ranging between 20 and 63 years (mean $41 \pm 73$ ) were from the urban area and $360(50 \%)$ with age ranging between 19 and 60 years (mean $39 \pm 64$ ) were from the rural area, and $482(66.9 \%)$ were males and $238(33.1 \%)$ were females. Fifty-seven (7.9\%) were illiterate, 167(23.2\%) had primary education, 288 (40\%) had secondary education, and 208 (28.9\%) had higher education. There were 127 (17.6\%) students, 104 (14.4\%) workers, 327 (45.4\%) employees, and 162 (22.5\%) unemployed. Lastly, 219 (29.17\%) had a family member with CVS. Other demographic characteristics are shown in Table 1.

Out of the 720 participants, 630 (87.5\%), 336 (93.3\%) from the urban area and 294 (81.6\%) from the rural area, had heard or read about CVS. The sources of their knowledge were through physicians in 39 (5.4\%), public media in 335 (46.5\%), seeing someone with stroke in 455 $(63.2 \%)$, and from their study in the school in 9 (1.25\%) of the participants. Physicians, public media, and seeing someone with stroke were the most frequent sources of knowledge at the urban area (Table 2).

On asking open-ended question, most of the participants 494 (68.6\%) did not have knowledge about the risk factors of CVS. This finding was significantly more frequent in the rural than in the urban participants $(P<0.05)$.On asking close-ended questions, most of the participants considered hypertension 664 (92.2\%), smoking 523 (72.6\%), old age 490 (68.1\%), previous stroke 402 (55.8\%), previous transient ischemic attack 402 (55.8\%), obesity 359 (49.9\%), high serum cholesterol level 372 (51.7\%), and stress 431 (59.9\%) as the most frequent risk factors of CVS. The least frequent risk factors were diabetes mellitus $121(16.8 \%)$, family history 120 (22.2\%), alcohol intake 295 (41.0\%), and inactivity 260 (36.1\%). Diabetes mellitus, ischemic heart disease, 
Table 1 Demographic data of the urban and rural participants

\begin{tabular}{|c|c|c|c|}
\hline & Total & Urban & Rural \\
\hline & No. $=720$ & No. $=360$ & No. $=360$ \\
\hline \multicolumn{4}{|l|}{ Sex } \\
\hline Male & $482(66.9 \%)$ & $251(69.7 \%)$ & $231(64.2 \%)$ \\
\hline Female & $238(33.1 \%)$ & 109 (30.3\%) & $129(35.8 \%)$ \\
\hline \multicolumn{4}{|l|}{ Age } \\
\hline$<30$ & $311(43.2 \%)$ & $126(35 \%)$ & $185(51.4 \%)^{\S}$ \\
\hline $30-40$ & $180(25 \%)$ & 85 (33.6\%) & $95(26.4 \%)$ \\
\hline$>40$ & $229(31.8 \%)$ & $149(41.4 \%)^{*}$ & $80(22.2 \%)$ \\
\hline \multicolumn{4}{|l|}{ Level of education } \\
\hline Illiterate & 57 (7.9\%) & $21(5.8 \%)$ & $36(10 \%)$ \\
\hline Primary & $167(23.2 \%)$ & $76(21.1 \%)$ & $91(25.3 \%)$ \\
\hline Secondary & $288(40 \%)$ & 99 (27.5\%) & $169(46.9 \%)^{\S}$ \\
\hline Higher education & $208(28.9 \%)$ & $144(40 \%)^{*}$ & $64(17.8 \%)$ \\
\hline \multicolumn{4}{|l|}{ Occupation } \\
\hline Students & $127(17.6 \%)$ & $73(20.3 \%)$ & $54(15 \%)$ \\
\hline Workers & $104(14.4 \%)$ & $16(4.4 \%)$ & $88(24.4 \%)^{\S}$ \\
\hline Employee & $327(45.4 \%)$ & $201(55.8 \%)^{*}$ & $126(35 \%)$ \\
\hline Not working & $162(22.5 \%)$ & 70 (19.4\%) & $92(25.6 \%)$ \\
\hline Family member of CVS & 219 (29.17\%) & $173(48 \%)$ & $146(40.5 \%)$ \\
\hline
\end{tabular}

$x^{2}$ test, $(*)$ significant in comparison to rural, $\left({ }^{5}\right)$ significant in comparison to Urban

alcohol intake, smoking, and old age were significantly the most frequent risk factors in the urban than in the rural participants $(P<0.05)$ (Table 3$)$.

On asking open-ended questions, most of the participants 491 (68.2\%) did not have knowledge about the warning symptoms of CVS and there was no statistically significant difference between the rural and the urban participants $(P>0.05)$. On asking close-ended questions, most of the participants considered paralysis of one side of the body 589 (81.8\%), numbness of one side of the body 570 (79.2\%), loss of consciousness 537 (74.6\%), mouth deviation 509 (70.7\%), and speech disturbance $502(69.7 \%)$ were the most frequent warning symptoms of CVS, while the least frequent warning symptoms were

Table 2 Source of knowledge of cerebro-vascular stroke among urban and rural participants

\begin{tabular}{llll}
\hline & $\begin{array}{l}\text { Total } \\
\text { No. }=720\end{array}$ & $\begin{array}{l}\text { Urban } \\
\text { No. }=360\end{array}$ & $\begin{array}{l}\text { Rural } \\
\text { No. }=360\end{array}$ \\
\hline Seeing someone with stroke & $455(63.2 \%)$ & $256(71.1 \%)^{* *}$ & $199(55.2 \%)$ \\
Public media & $335(46.5 \%)$ & $248(68.9 \%)^{* *}$ & $87(24.1 \%)$ \\
Physicians & $39(5.4 \%)$ & $36(10 \%)^{*}$ & $3(0.8 \%)$ \\
From study in the school & $9(1.25 \%)$ & $4(1.1 \%)$ & $5(1.4 \%)$ \\
Do not know & $90(12.5 \%)$ & $24(6.7 \%)$ & $66(18.3 \%)^{\S}$
\end{tabular}

$x^{2}$ test, $(*)$ significant and $(* *)$ highly significant in comparison to rural, $\left({ }^{\S}\right)$ significant in comparison to urban loss of vision 227 (31.5\%), headache 286 (39.7\%), vomiting 153 (21.3\%), and dizziness 322 (44.7\%). Weakness of one part of the body, speech disturbance, loss of vision, headache, vomiting, and dizziness were significantly the most frequent warning symptoms in the urban than in the rural participants $(P>0.05)$ (Table 4$)$.

Regarding the most frequent action to be taken on seeing a patient with CVS, 619 (86.0\%) preferred to go directly to the hospital, 327 (45.4\%) preferred to go neurologist, 172 (23.9\%) preferred to call pharmacist, and 201 (27.9\%) preferred to call G P. One hundred six $(14.7 \%)$ and 61 (8.5\%) of participants preferred calling religious person and herbalist respectively, and $5(0.7 \%)$ did not know what to do. Four hundred fifty-five (63.2\%) participants preferred to go to the hospital within $4 \mathrm{~h}$ of the CVS, $143(19.9 \%)$ preferred to go to the hospital after $4 \mathrm{~h}$, and 122 (16.9\%) had no knowledge of what to do. There was a significant difference between urban and rural knowledge about the action to be taken when seeing a patient with CVS $(P<0.01)$. Going to the hospital was the most frequent action to be taken when seeing a patient with CVS according to urban and rural participants. However, there was significant difference regarding going to hospital within $4 \mathrm{~h}$ of beginning symptoms of CVS between urban and rural participants $(P<0.01)$ (Table 5).

\section{Discussion}

The success of programs aiming at improving the life of people with CVS depends on public awareness and attitudes toward this disease. The level of knowledge regarding CVS was still inadequate even among medical staff and highly educated persons. However, they were found to have little or inadequate knowledge about some aspects of this serious condition such as the risk factors and warning symptoms.

\section{Sources of information}

In our study, the main sources of knowledge about CVS were from seeing someone with stroke in $63.2 \%$ followed by public media in $46.5 \%$. But the most striking result was that $5.4 \%$ of participants got their information from physicians, at the same time $29.17 \%$ of the participants had family member with CVS. This is almost consistent with all of the previous studies where there were variations between studies about the sources of information about CVS. According to the study conducted in Benin [10], 25.1\% had heard about stroke from their relatives; $13.9 \%$ from television, radio, and the Internet; $11.7 \%$ from rumors; $9.5 \%$ from school and their general culture; $11.8 \%$ from physicians; and $20.4 \%$ did not have a specific source of information or could not recall.

Similar reports from Pakistan [11] showed that $56 \%$ of their study population got their information from a 
Table 3 Knowledge of the risk factors of cerebro-vascular stroke among urban and rural participants

\begin{tabular}{|c|c|c|c|}
\hline & Total & Urban & Rural \\
\hline & No. $=720$ & No. $=360$ & No. $=360$ \\
\hline \multicolumn{4}{|l|}{ Open-ended question } \\
\hline Hypertension & 114(15.8) & $79(21.9 \%)^{*}$ & $35(9.7 \%)$ \\
\hline Stress & $112(15.6 \%)$ & $58(16.1 \%)$ & $54(15 \%)$ \\
\hline Do not know & $494(68.6 \%)$ & $223(61.9 \%)$ & $271(75.3 \%)^{\S}$ \\
\hline \multicolumn{4}{|l|}{ Close-ended questions } \\
\hline Hypertension & $664(92.2 \%)$ & $336(93 \%)$ & 328(91.1\%) \\
\hline Smoking & $523(72.6 \%)$ & $295(81.9 \%)^{*}$ & $228(63.3 \%)$ \\
\hline Old age & $490(68.1 \%)$ & $280(77.8 \%)^{*}$ & $214(59.4 \%)$ \\
\hline Ischemic Heart Disease & $487(67.6 \%)$ & $283(78.6 \%)^{* *}$ & $208(57.8 \%)$ \\
\hline Stress & $431(59.9 \%)$ & $247(68.6 \%) * *$ & $184(51.1 \%)$ \\
\hline Previous stroke & $402(55.8 \%)$ & $218(60.6 \%)^{* *}$ & 132(36.7\%) \\
\hline Previous transient ischemic attack & $402(55.8 \%)$ & $294(81.7 \%) * *$ & 108(30\%) \\
\hline Obesity & $359(49.9 \%)$ & $243(67.5 \%)^{* *}$ & $116(32.2 \%)$ \\
\hline High cholesterol & $372(51.7 \%)$ & $224(62.2 \%)$ & $215(59.8 \%)$ \\
\hline Alcohol intake & $295(41.0 \%)$ & $251(69.7 \%)^{* *}$ & $44(12.2 \%)$ \\
\hline Inactivity & $260(36.1 \%)$ & $228(63.3 \%) * *$ & $32(8.9 \%)$ \\
\hline Diabetes Mellitus & $121(16.8 \%)$ & $113(31.4 \%)^{* *}$ & $16(4.4 \%)$ \\
\hline Family history & 120 (22.2\%) & $145(40.3 \%)^{* *}$ & $20(5.6 \%)$ \\
\hline
\end{tabular}

$x^{2}$ test, $\left(^{*}\right)$ significant and $\left(^{* *}\right)$ highly significant in comparison to rural, $\left(^{(}\right)$significant in comparison to urban

Table 4 Knowledge of the warning symptoms of cerebrovascular stroke among urban and rural participants

\begin{tabular}{llll}
\hline & $\begin{array}{l}\text { Total } \\
\text { No. }=720\end{array}$ & $\begin{array}{l}\text { Urban } \\
\text { No. }=360\end{array}$ & $\begin{array}{l}\text { Rural } \\
\text { No. }=360\end{array}$ \\
\hline $\begin{array}{llll}\text { Open-ended question } \\
\text { Paralysis }\end{array}$ & $194(26.9 \%)$ & $112(31.1 \%)^{*}$ & $82(22.8 \%)$ \\
Altered consciousness & $35(4.9 \%)$ & $4(1.1 \%)$ & $31(8.6 \%)^{\S}$ \\
Do not know & $491(68.2 \%)$ & $244(67.8 \%)$ & $247(68.6 \%)$ \\
Close-ended questions & & & \\
Paralysis of one side & $589(81.8 \%)$ & $97(82.5 \%)$ & $292(81.8 \%)$ \\
Numbness of one side & $570(79.2 \%)$ & $308(85.6 \%)^{*}$ & $262(72.2 \%)$ \\
Altered consciousness & $537(74.6 \%)$ & $273(75.8 \%)$ & $264(73.3 \%)$ \\
Mouth deviation & $509(70.7 \%)$ & $273(75.8 \%)^{*}$ & $236(65.6 \%)$ \\
Speech disturbance & $502(69.7 \%)$ & $288(80.0 \%)^{* *}$ & $214(59.4 \%)$ \\
Dizziness & $322(44.7 \%)$ & $254(70.6 \%)^{* *}$ & $68(18.9 \%)$ \\
Weakness of one & $294(40.8 \%)$ & $262(72.8 \%))^{* *}$ & $32(8.9 \%)$ \\
Part of the body & & & \\
Headache & $286(39.7 \%)$ & $206(57.2 \%)^{* *}$ & $80(22.2 \%)$ \\
Loss of vision & $227(31.5 \%)$ & $203(56.4 \%)^{* *}$ & $24(6.7 \%)$ \\
Vomiting & $153(21.3 \%)$ & $145(40.3 \%)^{* *}$ & $8(2.2 \%)$ \\
\hline$X^{2}$ test, & & &
\end{tabular}

$x^{2}$ test, $\left(^{*}\right)$ significant and $\left({ }^{* *}\right)$ highly significant in comparison to rural, $\left({ }^{(}\right)$ significant in comparison to urban friend or relative, $30.9 \%$ had information because they had a stroke patient in the family, and $20 \%$ have learnt about stroke from television. In Oman [12], the majority of subjects $45.2 \%$ obtained their information mainly by personal experiences through the community, $39.3 \%$ from relatives, $14.7 \%$ from friends, $3.7 \%$ from newspapers, and $0.8 \%$ from

Table 5 Knowledge of the action to be taken and the preferred time to go to the hospital when seeing a patient with of cerebro-vascular stroke among urban and rural participants

\begin{tabular}{llll}
\hline & $\begin{array}{l}\text { Total } \\
\text { No. }=720\end{array}$ & $\begin{array}{l}\text { Urban } \\
\text { No. }=360\end{array}$ & $\begin{array}{l}\text { Rural } \\
\text { No. }=360\end{array}$ \\
\hline Action to be taken & & & \\
Direct to hospital & $619(86.0 \%)$ & $344(95.6 \%)^{* *}$ & $275(76.4 \%)$ \\
Go to neurologist & $327(45.4 \%)$ & $231(64.2 \%)^{* *}$ & $96(26.7 \%)$ \\
Call GP & $201(27.9 \%)$ & $24(6.7 \%)$ & $177(49.2 \%)^{\S}$ \\
Call pharmacist & $172(23.9 \%)$ & $8(2.2 \%)$ & $164(45.6 \%)^{\S}$ \\
Call religious person & $106(14.7 \%)$ & $4(1.1 \%)$ & $102(28.3 \%)^{\S}$ \\
Call herbalist & $61(8.5 \%)$ & $4(1.1 \%)$ & $57(15.8 \%)^{\S}$ \\
Did not know & $5(0.7 \%)$ & $0(0 \%)$ & $5(1.4 \%)$ \\
Time to go to the hospital & & & $103(28.6 \%)$ \\
Within 4h & $455(63.2 \%)$ & $352(97.8 \%)^{* *}$ & $143(39.7 \%)^{\S}$ \\
After 4 h & $143(19.9 \%)$ & $0(0 \%)$ & $114(31.7 \%)^{\S}$ \\
Did not know & $122(16.9 \%)$ & $8(2.2 \%)$ &
\end{tabular}

$X^{2}$ test, $\left(^{* *}\right)$ highly significant in comparison to rural, $\left({ }^{5}\right)$ significant in comparison to urban 
television. But the surprising thing was that only $4.5 \%$ of subjects got their information about stroke from health professionals. According to Ain Shams and Fayoum University study [13], 34.3\% got their information from seeing someone with stroke, $20.7 \%$ from mass media, $16 \%$ from reading about stroke, and $14.1 \%$ from school/university education. This result indicates that almost all physicians have no time to educate caregivers.

\section{Risk factors of CSV}

In the current study, the main risk factor for CVS was hypertension in $15.8 \%$, followed by stress in $15.6 \%$ of the participants when open-ended questions were asked. The ability to identify risk factors appeared to be strongly related to how the questions were asked. When close-ended questions were asked, hypertension and stress as risk factors for CVS had risen to $92.2 \%$ and $59.9 \%$, respectively. This result was in agreement with different studies that showed the most frequent identifiable risk factor for stroke was as follows. In Ain Shams and Fayoum University study [13], 73.8\% was hypertension and 54.9\% was stress; in Spain [8], 92\% was hypertension; in South Korea [14], 68\% was stress; in Georgia [15], 96\% was hypertension; in Hong Kong [16], 90\% was hypertension; in UK [17], 94.1\% was hypertension; in Benin [10], 34.5\% was hypertension and $7.6 \%$ was stress; in India [18], 54\% was hypertension; in Pakistan [11], 69.1\% was hypertension and 55.8\% was stress; and in Oman [12], 34.5\% was hypertension.

The difference between results of open- and close-ended questions in current study may be contributed to the educational level as $71 \%$ of participants in our study were illiterate or had primary and secondary education. The results of Ain Shams and Fayoum University study [13] were better than those of our study because their participants were workers in university hospitals.

In our study, diabetes mellitus was less frequent risk factor for CVS as $16.8 \%$ of participants reported it when close-ended question was asked. This result was negative when compared to previous studies about diabetes mellitus as risk factor for CVS in UK [17] 62.4\%, in Hong Kong [16] 60\%, in Spain [8] 59\%, in Georgia [15] 69\%, in India [18] 31\%, in Pakistan [11] 33.4\%, and in Oman [12] $22.8 \%$, while this result was positive when compared to the result of Benin [10] 0.3\%.

\section{Warning symptoms of CVS}

Paralysis of one side of the body was identified by $26.9 \%$ of our participants as the commonest warning symptom when open-ended question was asked and this is comparable to $65 \%$ reported from Oman [12], 62.2\% reported from India [18], 62\% from Hong Kong[16], 60\% from South Korea [14], 24\% from Georgia [15], and 88\% from Spain [8]. When close-ended questions were asked, it had risen to $81.8 \%$.

Only $4.9 \%$ of our participants were able to recognize altered consciousness as a stroke warning symptom in comparison to $58 \%$ reported in a study conducted in Hong Kong [16], 4\% in South Korea [14], 80\% in Spain [8], 34.2\% in Fayoum and Ain shams universities [13], and $13.3 \%$ in Nigeria [19]. When close-ended questions were asked, it had risen to $74.6 \%$.

Numbness of one side of the body has been reported by $79.2 \%$ of our participants with close-ended questions, and no one mentioned it in open-ended question in comparison to $92 \%$ with close-ended question and $2 \%$ with open-ended question in West Virginia [7], 24\% with open-ended question in South Korea [14], 95\% with close-ended question in Georgia [15], 69 \% with open-ended question in Spain [8], and $60.6 \%$ with open-ended question in Pakistan [11].

Speech disturbance was reported by $69.7 \%$ with closeended question of our participants in comparison to Ireland [20] 54\% with open-ended question, West Virginia [7] 88\% with close-ended question, Oman [12] 30\% with open-ended question, Hong Kong [16] 65\% with open-ended question, Georgia [15] 93\% with close-ended question and 16\% with open-ended question, Spain [8] 80\% with open-ended question, Pakistan [11] 41.2\% with open-ended question, and Benin [10] 12.8\% with open-ended question.

The ability to identify warning symptoms of CVS appeared to be strongly related to how the questions were asked. Unfortunately $68.2 \%$ of our participants did not know any warning symptoms of CVS. These results were negative when compared to Oman [12] 32.0\%, India [18] $29 \%$, and Benin [10] 27.2\%. Again lack of awareness was predominant in our results; it was higher among illiterates and associated with low educational role of physicians.

\section{Actions to be taken by the participants when seeing a patient with CVS}

The most frequent actions to be taken when seeing a patient with CVS were going directly to hospital in $86 \%$ followed by going to neurologist in $45.4 \%$ when close-ended question was asked. These results agreed with West Virginia study [7] as 94\% go to hospital and 94\% call 911; in Spain [8], 45\% call emergency and 41\%call GP; in Hong Kong [16], 49\% call emergency and 29\% go to hospital; in Australia [4], 67\% call emergency and $23 \%$ go to hospital; in Ain Shams and Fayoum [13], 56.1\% go to hospital followed by $32.1 \%$ contact a specialist physician; in Benin [10], 94.1\% of subjects reported that they go to a hospital; in Pakistan [11], the response was to take individual to emergency department/ hospital in 26.16\% of participants; and in Oman [12], 73.0\% of subjects reported that they would go immediately to a hospital emergency department.

In this study, call religious person and call herbalist were $14.7 \%$ and $8.5 \%$ respectively in comparison to $4.5 \%$ 
and $0.3 \%$ according to Ain Shams and Fayoum Universities [13]. Approximately $1.1 \%$ of urban participants call religious person in comparison to $28.3 \%$ in rural participants. About $97.8 \%$ of urban participants preferred to go to the hospital within $4 \mathrm{~h}$ of CVS in comparison to $28.6 \%$ in rural participants. These results mostly reflect school educational level difference.

\section{Conclusion}

This study concluded that hypertension is the best known risk factor of CVS. Only few subjects were aware of diabetes mellitus as risk factors for stroke. This information appears useful for planning information and stroke prevention campaigns. Based on our participants' specified sources of information on stroke, educational efforts are possible in the mass media and should be used to encourage general practitioners to educate their patients, especially those at increased risk. Knowing the fact that increase the awareness of the target group at risk would greatly alleviate the stroke outcome and increase the responsibility of physicians and neurologists of giving more effort to educate their patients and relatives.

\section{Acknowledgements}

Not applicable.

\section{Funding}

The authors were responsible for the cost of this study including the design of the study and collection, analysis, and interpretation of data and in writing the manuscript, and there was no funding.

\section{Availability of data and materials}

The data can be publicly available at the Faculty of Medicine, Suez Canal University.

\section{Authors' contributions}

OA carried out the study conception and design, participated in its design and coordination, and drafted the manuscript. AY carried out the design of the study and the analysis and interpretation of data and helped to draft the manuscript. AR participated in the sequence alignment, performed the statistical analysis, and drafted the manuscript. Ml participated in the acquisition of data. All authors read and approved the final manuscript.

\section{Ethics approval and consent to participate}

The study was approved by the Ethics committee of Suez Canal Faculty of medicine in May 27, 2013.

Committee Number: 976.

An informed consent was taken from all the participants in the study.

\section{Consent for publication}

Participants signed an informed consent for publication.

\section{Competing interests}

The authors declare that they have no competing interests.

\section{Publisher's Note}

Springer Nature remains neutral with regard to jurisdictional claims in published maps and institutional affiliations.

\section{Author details}

${ }^{1}$ Department of Neuropsychiatry, Faculty of Medicine, Suez Canal University, Ismailia, Egypt. ²Dar El-Shefaa General Hospital, Cairo, Egypt.
Received: 2 October 2017 Accepted: 22 April 2019

Published online: 22 May 2019

\section{References}

1. WHO MONICA Project Investigators. The World Health Organization MONICA Project (Monitoring trends and determinants in cardiovascular disease). J Clin Epidemiol. 1988;41:105-14.

2. Donnan GA, Fisher M, Macleod M, Davis SM. Stroke. Lancet. 2008;371: 1612-23.

3. Evenson KR, Rosamond WD, Morris DL. Pre-hospital and in-hospital delays in acute stroke care. Neuroepidemiology. 2001;20:65-76.

4. Yoon SS, Heller RF, Levi C, Wiggers J, Fitzgerald PE. Knowledge of stroke risk factors, warning symptoms and treatment among an Australian urban population. Stroke. 2001;32:1926-30.

5. Srivastava AK, Prasad K. A study of factors delaying hospital arrival of patients with acute stroke. Neurol India. 2001;49:272-6.

6. Das S, Banerjee T. Stroke: Indian scenario. Circulation. 2008;118:2719-24.

7. Alkadry MG, Wilson C, Nicholas D. Stroke awareness among rural residents: the case of West Virginia. Soc Work Health Care. 2005;42:73-92.

8. Segura T, Vega G, Lopez S, Rubio F and Castillo J : on behalf of the Cerebrovascular Diseases Study Group of the Spanish Society of Neurology. Public perception of stroke in Spain. Cerebrovasc Dis 2003:16:21-26.

9. Müller-Nordhorn J, Nolte CH, Rossnagel K. Knowledge about risk factors for stroke: a population-based survey with 28,090 participants. Stroke. 2006: 37(4):946-50.

10. Cossi M, Preux P, Chabriat H, Gobron C, Houinato D. Knowledge of stroke among an urban population in Cotonou (Benin); 2012.

11. Aly Z, Abbas K, Kazim SF, Taj F, Aziz F, Irfan A, Sheikh R, Shakir M, Javed SM, Fatmi Z. Awareness of stroke risk factors, signs and treatment in a Pakistani population. JPMA. 2009;59:495.

12. Al Shafaee MA, Ganguly SS, Al Asmi AR. Perception of stroke and knowledge of potential risk factors among Omani patients at increased risk for stroke. BMC Neurol. 2006;6:38.

13. Emara TH, Moustafa RR, Bar AA, Abuzeid SH, El Sherbiny N, Ghaffar HA, ElMously S. Knowledge and attitudes towards stroke among worker in two university hospitals. Egypt J Neurol Psychiat Neurosurg. 2013;50(1):49-54.

14. Kim JS, Sung S, Yoon RN. Perspectives of stroke in persons living in Seoul. South Korea Stroke. 1997;28:1165-9.

15. Rowe AK, Frankel MR, Sanders KA. Stroke awareness among Georgia adults: epidemiology and considerations regarding measurement. South Med J. 2001;94:613-8.

16. Cheung RTF, li LSW, Mak W. Knowledge of stroke in Hong Kong. Cerebrovasc Dis. 1999;9:119-23.

17. Bietzk E, Davies R, Floyd A, Lindsay A, Greenstone H, Symonds A, Greenfield S. FAST enough? The UK general public's understanding of stroke. Clin Med. 2012;12(5):410-5.

18. Pandian JD, Jaison A, Deepak SS, Kalra G, Shamsher S, Lincoln DJ, Abraham G. Public awareness of warning symptoms, risk factors, and treatment of stroke in northwest India. Stroke. 2005;36:644-8.

19. Wahab KW, Okokhere PO, Ugheoke AJ, Oziegbe O, Asalu AF, Salami TA. Awareness of warning signs among suburban Nigerians at high risk for stroke is poor: a cross-sectional study. BMC Neurol. 2008;8:18.

20. Parahoo K, Thompson K, Cooper M, Stringer M, Ennis E, McCollam P. Stroke: awareness of the signs, symptoms and risk factors: a population-based survey. Cerebrovasc Dis. 2003;16:134-40. 